Article

\title{
Zeylenone Induces Mitochondrial Apoptosis and Inhibits Migration and Invasion in Gastric Cancer
}

\author{
Shuxian Yang ${ }^{(\mathbb{D}}$, Yonghong Liao, Liyong Li, Xudong $\mathrm{Xu}$ and Li Cao * \\ Institute of Medicinal Plant Development, Chinese Academy of Medical Sciences \& Peking Union Medical \\ College, Beijing 100193, China; Yangshuxianlove@163.com (S.Y.); yhliao@implad.ac.cn (Y.L.); \\ 1ly0916@sina.com (L.L.); xdxu@implad.ac.cn (X.X.) \\ * Correspondence: lcao@implad.ac.cn; Tel.: +86-10-57833222
}

Received: 8 August 2018; Accepted: 23 August 2018; Published: 27 August 2018

\begin{abstract}
The mortality of gastric cancer (GC) is increasing due to its high rates of recurrence and metastasis. Zeylenone (Zey), a type of naturally occurring cyclohexene oxide, was demonstrated to be effective in cancer patients. The aim of this study is to explore the anti-cancer effect of Zey against gastric cancer both in vitro and in vivo, as well as the underlying mechanisms. We found that Zey inhibited gastric tumor growth, as demonstrated by in vitro gastric cancer cell lines and in a human gastric cancer xenograft mouse model. Furthermore, Zey induced substantial apoptosis through a mitochondrial apoptotic pathway, involving mitochondrial transmembrane potential loss, caspase-3 activation, anti-apoptotic protein downregulation, and pro-apoptotic protein upregulation. Notably, we revealed for the first time that Zey suppressed invasion and migration by wound healing and transwell chamber assays. Through Western blotting, we further explored the potential mechanism of Zey's anti-cancer activity. We found that Zey downregulated the expression of matrix metalloproteinase 2/9 (MMP 2/9) and inhibited the phosphorylation of AKT and ERK. In short, Zey, which induced mitochondrial apoptosis and inhibited proliferation, migration, and invasion, may be developed as a novel drug for the treatment of gastric cancer.
\end{abstract}

Keywords: Zeylenone; gastric cancer; invasion; migration; apoptosis

\section{Introduction}

Gastric cancer (GC) represents a health threat as the fourth most common cancer and the second leading cause of cancer death worldwide [1,2]. Studies showed that more than 950,000 new diagnoses are made every year, and an estimated 720,000 patients died from gastric cancer in 2012 [3]. Even with the rapid improvement of healthcare and detection [4], gastric cancer is still a nightmare, and the relative five-year survival rates for GC are only about $20 \%$ in most areas of the world [5]. Thus, the burden of gastric cancer remains high, especially in Asia, Latin America, and central and eastern Europe [6]. Furthermore, gastric cancer is characterized by uncontrolled cell proliferation and metastasis [2]. Therefore, most patients do not die due to the primary cancer, but from metastatic cancer [7]. However, research into the field of metastasis, compared with other key events such as proliferation, is lacking. Hence, identifying new drugs with anti-metastasis and anti-proliferation characteristics is now the focus in GC treatment.

Naturally occurring bioactive phytochemicals with low toxicity emerged as promising options for the development of effective alternatives for conventional treatments. Zeylenone (Zey) [8], isolated from ethanol extracts of the leaves of Uvaria grandiflora Roxb., is a cyclohexene oxide [9], which exhibits anti-cancer activity and is regarded as a soft drug. In 2010-2012, we successfully attained mPEG-PLGA-loaded Zeylenone nanomicelles, which improved the solubility and stability of Zey and achieved sustained release. The drug-loaded micelles were also characterized in terms of 
drug encapsulation, dynamic size, zeta potential, drug stability, and release, involving not just in vitro release assays, but also in vivo pharmacokinetic studies [8]. In addition, previous studies by our group indicated that Zey displayed strong cytotoxic activity against acute lymphoblastic leukemia cells [10] and cervical cancer cells [11] in a dose-dependent manner, indicating its strong antitumor activity. However, to the best of our knowledge, the effect of Zey on gastric cancer is yet to be studied in detail, especially the effect of Zey on gastric cancer invasion and migration.

In view of the above, there is an interest in studying the potential effects and mechanisms of Zey against GC. In this study, we found that Zey inhibited gastric tumor growth, as demonstrated by in vitro gastric cancer cell lines and in a human gastric cancer xenograft mouse model. Our further studies revealed that Zey induced substantial apoptosis of GC cells, which was associated with the mitochondrial apoptotic pathway. In addition, Zey also suppressed the invasion and migration of gastric cancer cells by wound healing and transwell chamber assays.

The activation of the AKT and ERK pathway is necessary for tumor initiation and progression, including cell growth, metastasis, and resistance to chemotherapy [12]; thus, these pathways are worth studying [13]. ERK is an important member of the MAPK family, which plays a central role in regulating the expressions of matrix metalloproteinases (MMPs) [14]. MMPs, a family of zinc-dependent neutral endopeptidases, are involved in the metastasis of cancer because of their ability to hydrolyze various extracellular matrix (ECM) components [15]. Of note, MMP-2 and MMP-9 can degrade most ECM components, accelerating metastasis [16]. Through Western blotting, we further explored the potential mechanism of Zey's anti-cancer activity. We found that Zey suppressed the metastasis of gastric cancer cells by decreasing protein levels of MMP-2 and MMP-9 and inhibiting the phosphorylation of AKT, ERK, and mTOR. According to the above experimental results, we conclude that Zey may be developed into a novel therapeutic agent for gastric cancer treatment due to its strong ability to inhibit migration and invasion and to induce apoptosis.

\section{Results}

\subsection{Zey Inhibits Gastric Cancer Cell Proliferation}

The chemical structure of Zey is shown in Figure 1A. An MTT assay and colony formation assay were performed to determine the anti-proliferative effect of Zey on SGC7901 and MGC803 cells. As shown in Figure 1B,C, Zey treatments reduced the cell viability of the SGC7901 and MGC803 cells in a dose-dependent manner without severe toxicity to normal gastric epithelial cells (GES-1). Similar results from a colony formation assay confirmed that Zey-treated groups exhibited smaller and fewer colonies compared to untreated cells (Figure 1D,E). However, low concentrations of Zey $(<3 \mu \mathrm{M})$ did not significantly inhibit cell viability. IC 50 values of Zey were detected as $13.21 \mu \mathrm{M}$ for SGC7901 cells and $13.42 \mu \mathrm{M}$ for MGC803 cells. These data together indicated that Zey has anti-proliferation activity in gastric cancer cells.
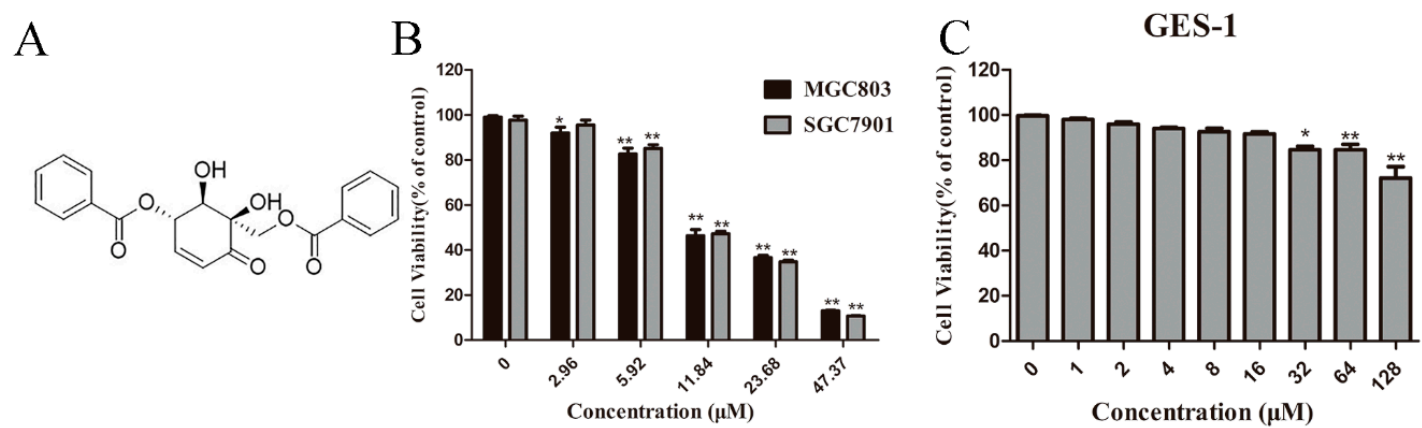

Figure 1. Cont. 

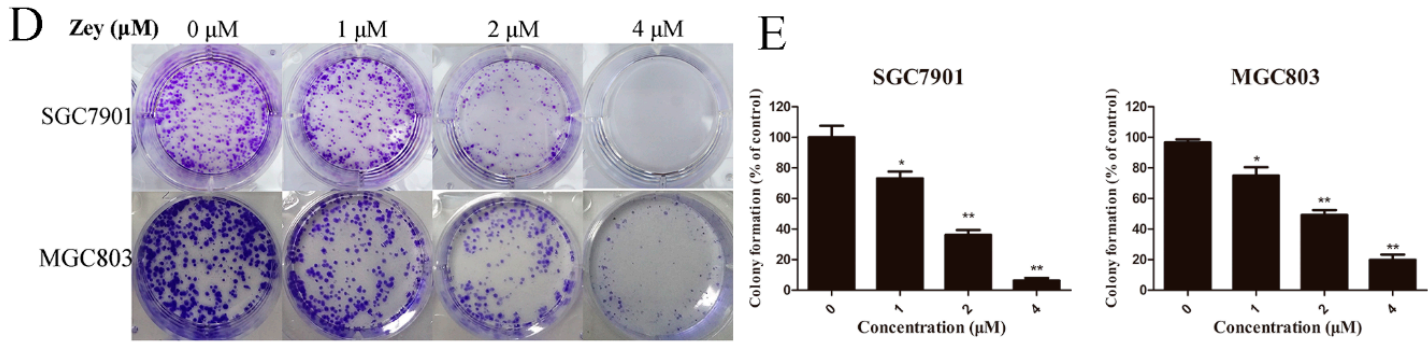

Figure 1. Zeylenone (Zey) effectively suppresses cell viability and colony formation in SGC7901 and MGC803 cells. (A) Chemical structure of Zey. (B) Zey suppresses the viability of SGC7901 and MGC803 cells determined in an MTT assay. Cells were treated with Zey $(0,2.96,5.92,11.84,23.68$, or $47.37 \mu \mathrm{M})$ for $24 \mathrm{~h}$. Data are expressed as means \pm SD of three distinct experiments. The cell viability of the control (DMSO only) is indicated as $100 \%{ }^{*} p<0.05$ and ${ }^{* *} p<0.01$ vs. control cells. (C) Zey suppresses the viability of normal gastric epithelial (GES-1) cells determined in an MTT assay. GES-1 cells were treated with Zey $(0,1,2,4,8,16,32,64$, or $128 \mu \mathrm{M})$ for $24 \mathrm{~h}$. Data are expressed as means $\pm \mathrm{SD}$ of three distinct experiments. ${ }^{*} p<0.05$ and ${ }^{* *} p<0.01$ vs. control cells. (D) Representative images of colonies after SGC7901 and MGC803 cells were treated with Zey for 12 days. (E) Statistical analysis of colony numbers from three independent experiments. ${ }^{*} p<0.05$ and ${ }^{* *} p<0.01$ vs. control cells.

\subsection{Zey Induces Gastric Cancer Cell Apoptosis}

We further evaluated whether Zey inhibited cell proliferation by inducing cancer cell apoptosis. Firstly, Hoechst 33258 staining was used to study the morphological changes of GC cells. Based on $\mathrm{IC}_{50}$ values, we chose 3.3, 6.6, and $13.2 \mu \mathrm{M}$ as treatments for GC cells. After Hoechst 33258 staining, an increased number of cells with bright nuclear condensation or fragmented nuclei, which was regarded as characteristic of cell apoptosis, was observed after Zey treatment, while control cells exhibited round nuclei and the chromatin were well distributed (Figure 2A).

Next, we further assessed apoptosis using annexin V-FITC/PI apoptosis staining. After treatment with Zey for $12 \mathrm{~h}$, the apoptosis rate significantly increased in a dose-dependent manner in SGC7901 and MGC803 cells (Figure 2B-E). With the treatment time of Zey extended to $24 \mathrm{~h}$, at $13.2 \mu \mathrm{M}$, the apoptosis rates of SGC7901 and MGC803 cells reached up to $48.21 \%$ and $64.58 \%(p<0.01)$, respectively. Thus, Zey induced gastric carcinoma cell apoptosis in a dose- and time-dependent manner.
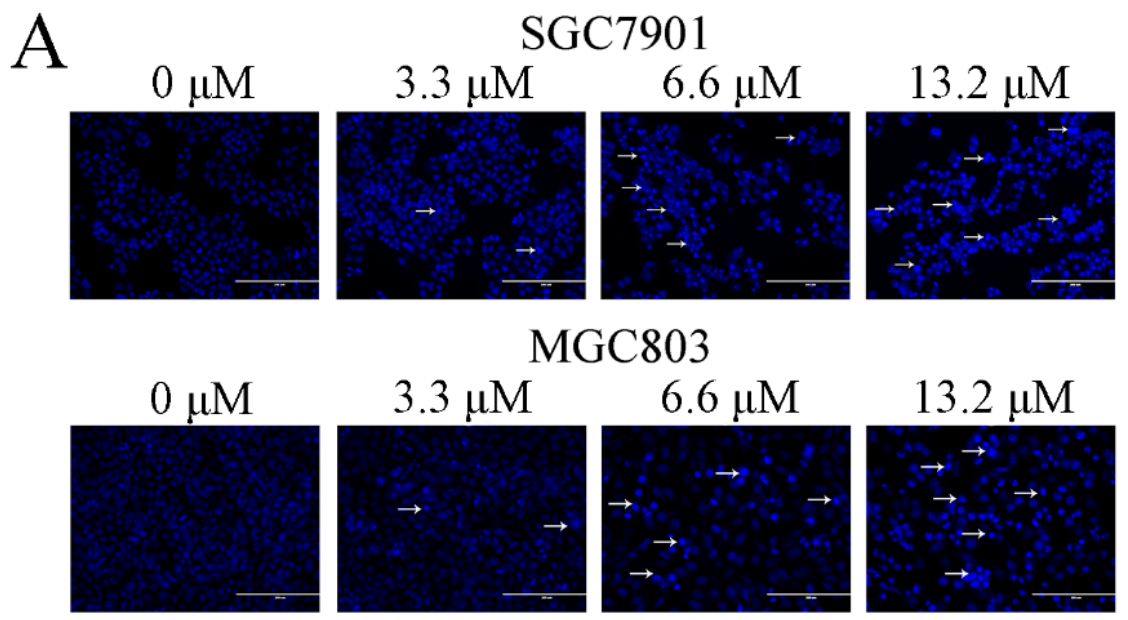

Figure 2. Cont. 
B
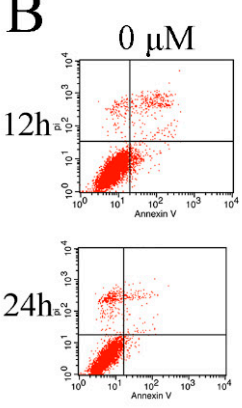

$\mathrm{D}$
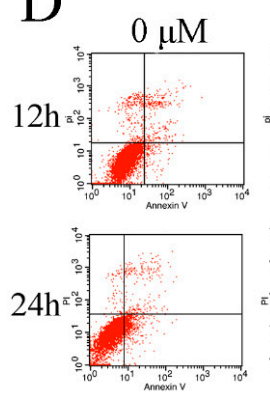

SGC7901
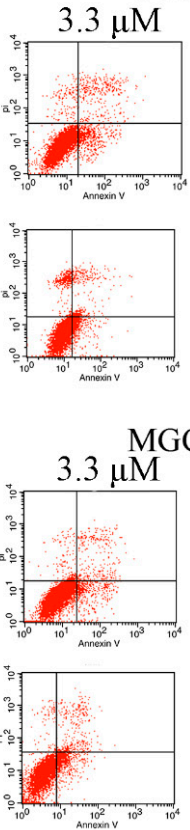
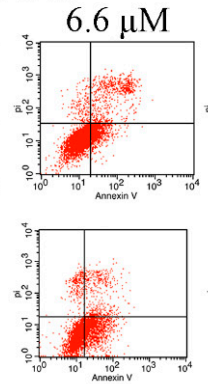

MGC803

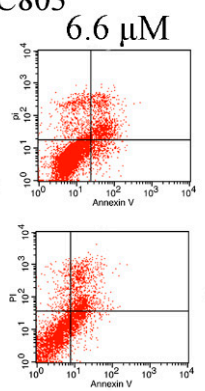

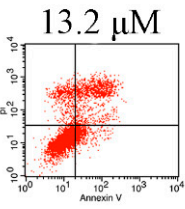
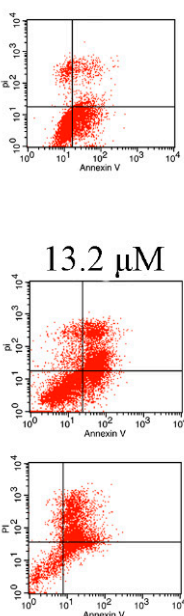

SGC7901

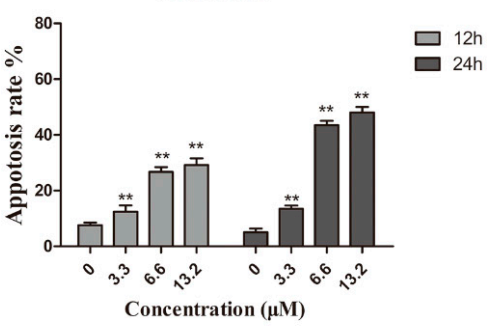

$\mathrm{E}$

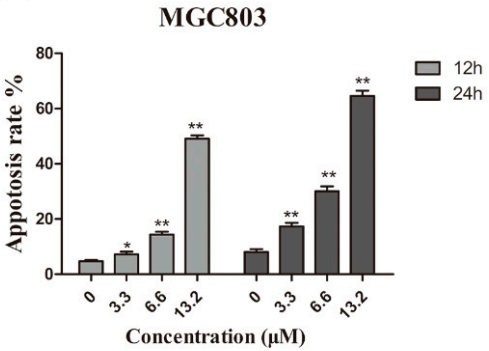

Figure 2. Zey induces apoptosis in SGC7901 and MGC803 cells. (A) Morphological changes of apoptosis were detected by Hoechst 33258 staining. Images are shown under a fluorescence microscope with a magnification of $200 \times$. (B,C) Apoptosis of SGC7901 cells detected by the Annexin V-FITC/PI staining test and the ratio of apoptotic cells. The data represented the means $\pm \mathrm{SD}$ for triplicate determinations. ${ }^{*} p<0.05$ and ${ }^{* *} p<0.01$ vs. control cells. (D,E) Apoptosis of MGC803 cells detected by the Annexin V-FITC/PI staining test and the ratio of apoptotic cells, including early apoptotic cells (lower right quadrant) and late apoptotic cells (upper right quadrant). The data represented the means $\pm \mathrm{SD}$ for triplicate determinations. ${ }^{*} p<0.05$ and ${ }^{* *} p<0.01$ vs. control cells.

\subsection{Zey Induces Apoptosis in Gastric Cancer Cells via the Mitochondrial Apoptosis Pathway}

To understand the underlying mechanism via which Zey induces apoptosis in GC cells, we investigated changes in the mitochondrial membrane potential and the level of corresponding proteins involved in apoptosis.

Initially, cells treated with or without Zey were stained with JC-1, and the changes in mitochondrial membrane potential were analyzed by flow cytometry. As shown in Figure $3 A, B$, when the concentration of Zey was $3.3 \mu \mathrm{M}$, the effect was obvious neither in SGC7901 cells nor in MGC803 cells. However, Zey treatment at $13.2 \mu \mathrm{M}$ induced a loss of mitochondrial membrane potential $(p<0.01)$.

Next, we further measured the effect of Zey on proteins related to apoptosis with Western blotting (Figure 3C). Zey treatment induced a significant decline in anti-apoptotic proteins Bcl-xl and Bcl-2 while significantly increasing the pro-apoptotic protein Bax. Consistently, Zey treatment markedly decreased the levels of pro-caspase-3, indicating that Zey treatment induced gastric cancer cell apoptosis via caspase- 3 activation and the involvement of anti-apoptotic proteins $\mathrm{Bcl}-\mathrm{xl}$ and $\mathrm{Bcl}-2$ and pro-apoptotic protein Bax. 
A

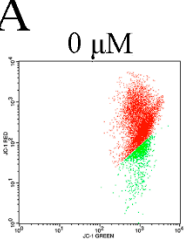

$0 \mu \mathrm{M}$

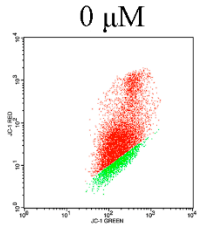

$\mathrm{C}$

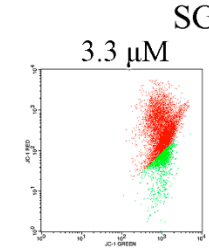

SGC790

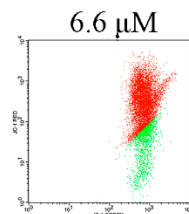

MGC803
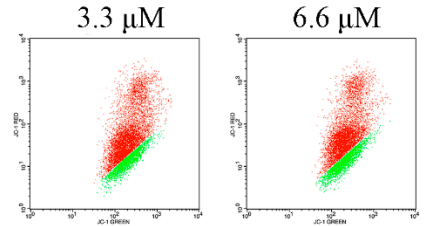

SGC7901

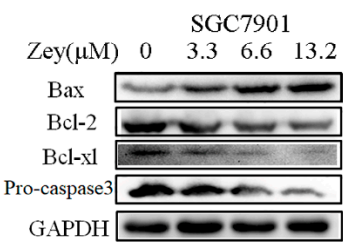

SGC7901

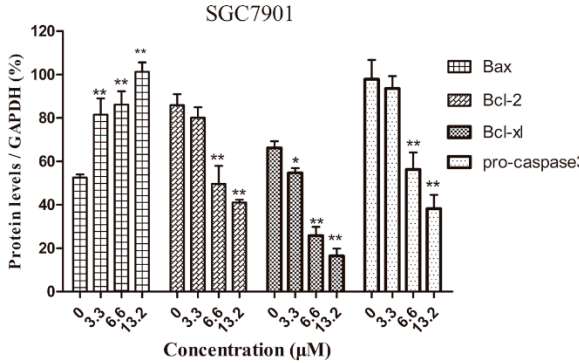

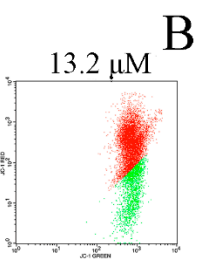

$13.2 \mu \mathrm{M}$

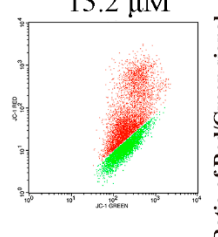

MGC803 $\begin{array}{lll}3.3 & 6.6 & 13.2\end{array}$

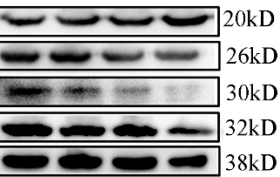

MGC 803

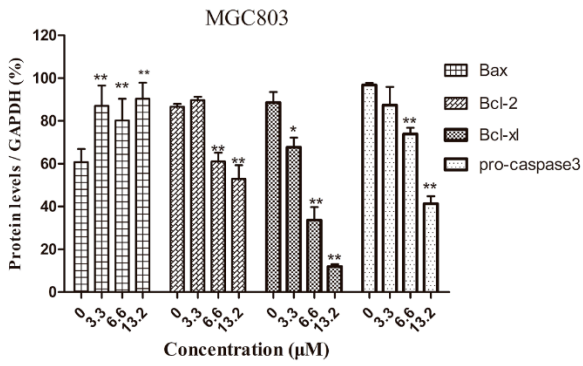

Figure 3. Zey induces apoptosis of SGC7901 and MGC803 cells through the initiation of the mitochondrial pathway. (A) Zey induced a loss of mitochondrial membrane potential in SGC7901 and MGC803 cells. Cells were treated with increasing concentrations of Zey for $24 \mathrm{~h}$, and mitochondrial membrane potential was analyzed by flow cytometry after cells were stained with JC-1. (B) Quantitative analysis of the ratio of red to green fluorescence. The data represented the means $\pm \mathrm{SD}$ for triplicate determinations. ${ }^{*} p<0.05$ and ** $p<0.01$ vs. control cells. (C) Apoptosis-related protein expression was detected by Western blot analysis in SGC7901 and MGC803 cells. Cells were incubated with Zey $(0,3.3,6.6$, or $13.2 \mu \mathrm{M})$ for $24 \mathrm{~h}$, and whole-cell lysates were analyzed. The data represented the means \pm SD for triplicate determinations. ${ }^{*} p<0.05$ and ** $p<0.01$ vs. control cells.

\subsection{Zey Inhibits the Migration and Invasion of Gastric Cancer Cells}

Previous studies demonstrated that cancer metastasis is highly related to cellular motility and degradation of the ECM [17]. We first examined the effect of Zey on motility in gastric cancer cells using a wound-healing assay. According to the cell viability data (Figure 1B), we chose Zey concentrations at 1,2 , and $4 \mu \mathrm{M}$ (with a cell viability rate $>93 \%$ ). As shown in Figure $4 \mathrm{~A}, \mathrm{~B}$, the wound-healing ability in SGC7901 cells decreased gradually in a dose-dependent manner with raised concentrations of Zey, consistent with the results in MGC803 cells. Of note, when the concentration of Zey increased to $2 \mu \mathrm{M}$ and $4 \mu \mathrm{M}$, the wound-healing rates of SGC7901 and MGC803 cells were reduced to $20.50 \%$ and $25.82 \%$ at $2 \mu \mathrm{M}$ and to $17.94 \%$ and $13.62 \%$ at $4 \mu \mathrm{M}$, respectively. At a low concentration $(1 \mu \mathrm{M})$, the effect was not as significant $(p>0.05)$.

Next, the effect of Zey on migration and invasion was also further determined with a transwell chamber assay. After treatment with Zey $(0,1,2$, or $4 \mu \mathrm{M})$ for $24 \mathrm{~h}$, the number of Zey-treated SGC7901 cells that invaded the lower chamber was significantly less than the control group $(p<0.01$, 
Figure $4 \mathrm{C}, \mathrm{D})$. At $4 \mu \mathrm{M}$, the invasion and migration rates of SGC7901 were $17.6 \%$ and $10.5 \%$, respectively. Then, the same effects were also discovered in MGC803 cells, with percentages of 25.7\% and 21.1\%, respectively. It can be seen that the effect of Zey on inhibiting invasion and migration in MGC803 cells was not as obvious as in SGC7901 cells. Collectively, these findings showed that Zey could inhibit migration and invasion of GC cells in a dose-dependent manner.

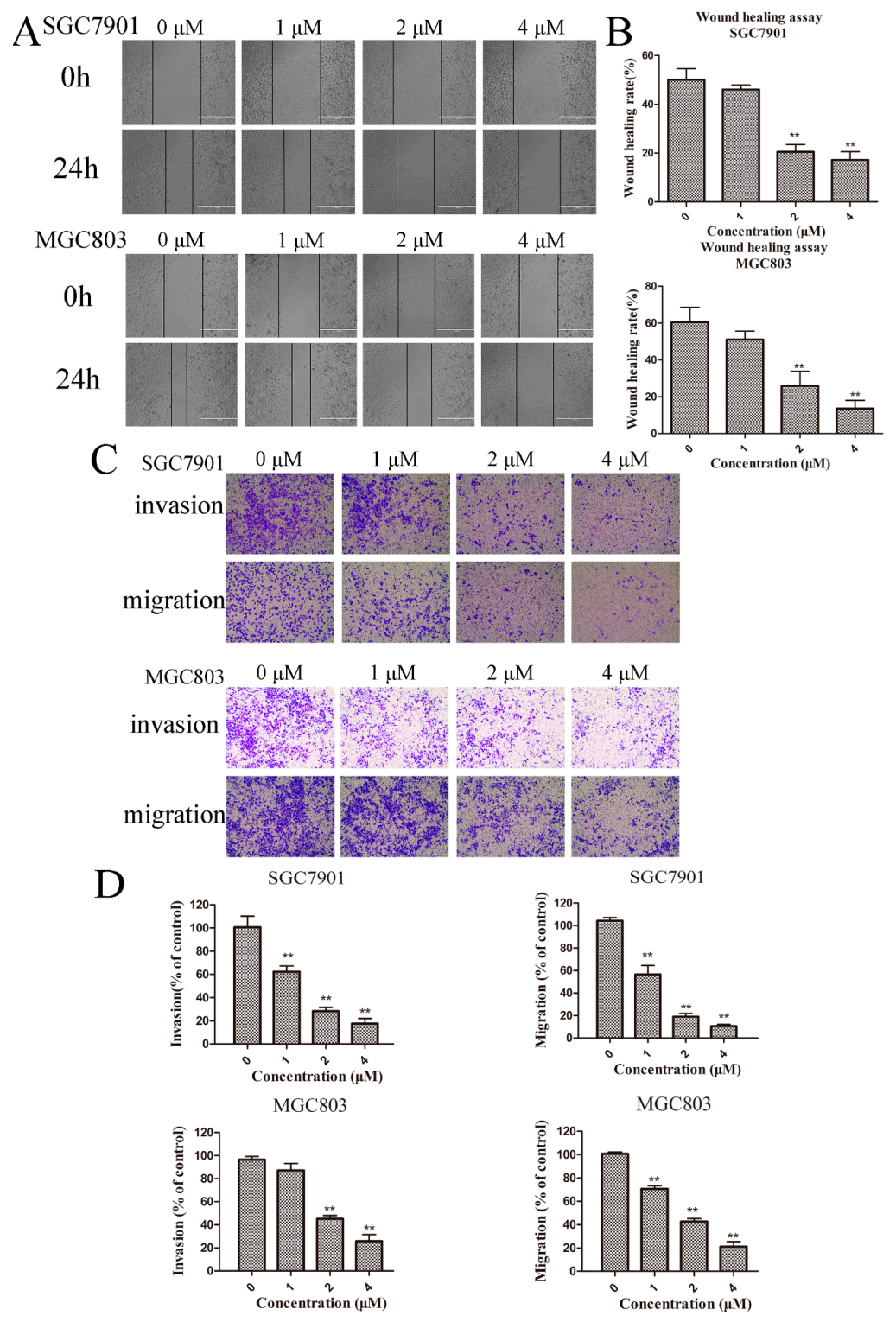

Figure 4. Zey inhibits the migration and invasion in SGC7901 and MGC803 cells. (A) Wound-healing assay in SGC7901 and MGC803 cells. After making a linear wound, cells were incubated with different concentrations of Zey $(0,1,2$, or $4 \mu \mathrm{M})$ in serum-free RPMI-1640 for an additional $24 \mathrm{~h}$. Wound healing was photographed at 0 and $24 \mathrm{~h}$ using a microscope with a magnification of $100 \times$. (B) Quantitative analysis of the ratio of wound healing. The data represented the means $\pm \mathrm{SD}$ for triplicate determinations. ${ }^{*} p<0.05$ and ${ }^{* *} p<0.01$ vs. control cells. (C) Invasion and migration assay in SGC7901 and MGC803 cells. Images are shown under a light microscope with a magnification of $100 \times$. (D) Quantitative analysis of the ratio of invasion/migration in SGC7901 and MGC803 cells. The data represented the means \pm SD of three distinct experiments. The control cells were regarded as $100 \%$ in the invasion/migration index calculation. ${ }^{*} p<0.05$ and ${ }^{* *} p<0.01$ vs. control cells. 


\subsection{Zey Attenuates AKT/MMP2/MMP9 and ERK Signaling Pathways in Gastric Cancer Cells}

To further understand the experimental results mentioned above, we continued exploring the possible mechanisms with Western blotting, particularly with MMP-2 and MMP-9 [18]. As shown in Figure 5A,B, Zey $(6.6$ and $13.2 \mu \mathrm{M})$ treatment significantly reduced the expressions of MMP-2 and MMP-9 compared with the control group $(p<0.01)$. With the concentration of Zey increased to $6.6 \mu \mathrm{M}$ and $13.2 \mu \mathrm{M}$, the inhibitory effect on the activity of MMP-2 and MMP-9 appeared to be more obvious. Activation of AKT accelerated cancer progression and distant metastasis. Our result showed that Zey blocked the phosphorylation of AKT and ERK in SGC7901 and MGC803 cells, and the result was consistent between SGC7901 and MGC803 cells. Collectively, these data indicated that the antitumor effect of Zey on SGC7901 and MGC803 cells is tightly correlated with the AKT/MMP2/MMP9 and ERK signaling pathways.

\subsection{Zey Suppresses Tumor Growth in a Mouse Xenograft Model}

To further validate the antitumor activity of Zey in vivo, we developed a xenograft model of GC, and tested the effects of Zey on tumor growth. After treatment with Zey for 10 days, the tumor growth in the Zey treatment groups was significantly slower compared with the control groups (Figure 6A). In detail, no significant difference in the tumor volume of the different groups was observed at the beginning of treatment. At the end of treatment, as expected, the tumor volume was smaller in the Zey $(30 \mathrm{mg} / \mathrm{kg})$ groups compared with the control groups $(p<0.01)$, as was paclitaxel. Alternatively, the isolated tumor weight was also remarkably reduced in the Zey-treated group $(30 \mathrm{mg} / \mathrm{kg})$ than in the control group (Figure 6B,C). Simultaneously, the tumor inhibition rates of Zey were $47.95 \%$ $(30 \mathrm{mg} / \mathrm{kg})$ and $48.11 \%(15 \mathrm{mg} / \mathrm{kg})$ in the paclitaxel group compared to the control group (Figure $6 \mathrm{~B})$. Moreover, the mouse body weights in the Zey-treated groups slightly decreased, but not obviously $(p>0.05)$, indicating that Zey was not significantly toxic (Figure 6D). Together, these data indicated that Zey could effectively inhibit gastric tumor growth in vivo. In the in vivo experiments reported here, the Zey was mPEG-PLGA-loaded Zeylenone nanomicelles. 
A

\section{B}

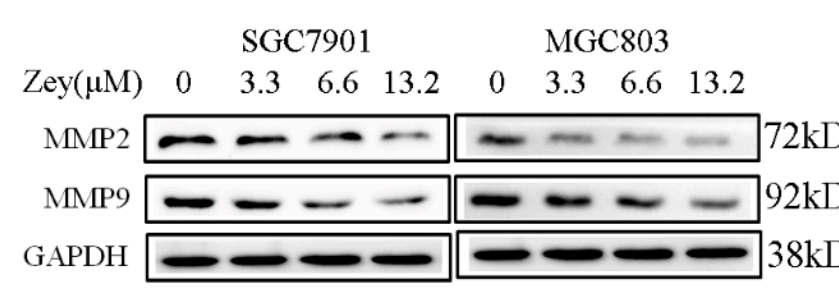

SGC7901

MGC803

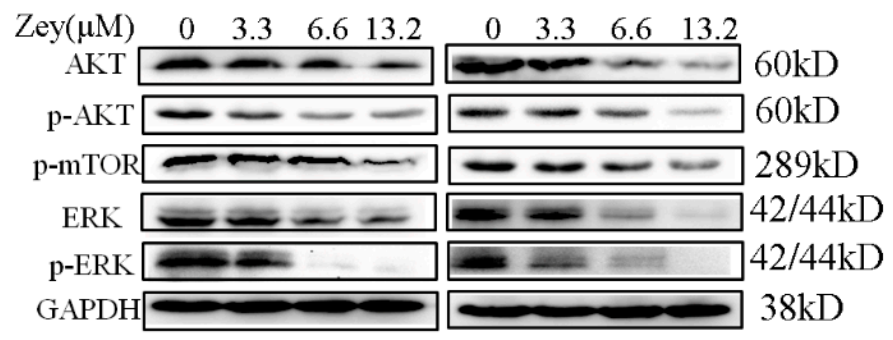

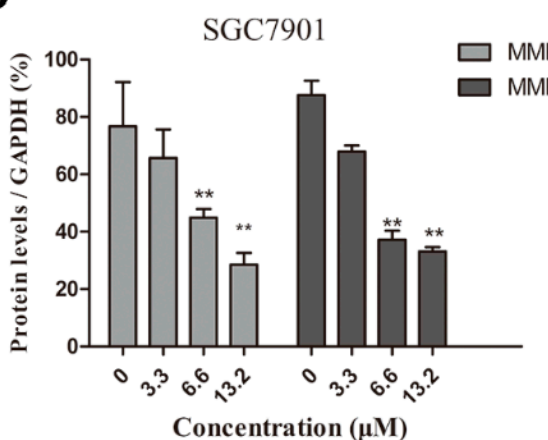

Concentration $(\mu \mathrm{M})$

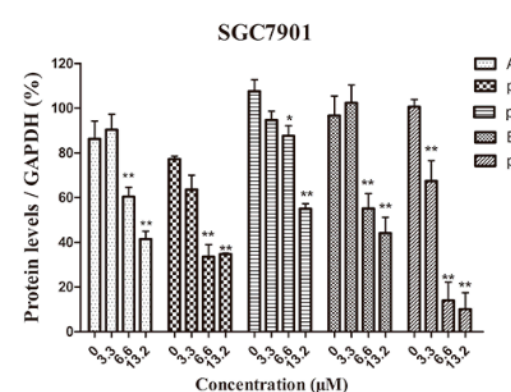

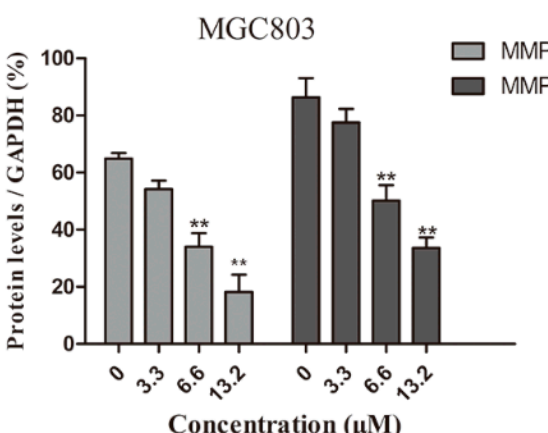

Concentration $(\mu \mathrm{M})$

MGC803

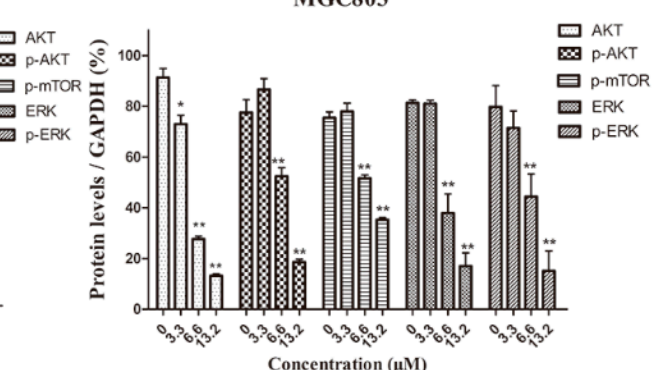

Figure 5. Zey attenuates AKT/matrix metalloproteinase 2 (MMP2)/MMP9, and ERK pathways in SGC7901 and MGC803 cells. (A) Immunoblot analyses of AKT, phosphorylated (p)-AKT, MMP-2, MMP-9, p-mTOR, ERK, and p-ERK in Zey-treated SGC7901 and MGC803 cells. (B) Quantitative analysis of protein levels. GAPDH was used to confirm equal protein loading. The data represented the means $\pm \mathrm{SD}$ for triplicate determinations. ${ }^{*} p<0.05$ and ${ }^{* *} p<0.01$ vs. control cells. 
A

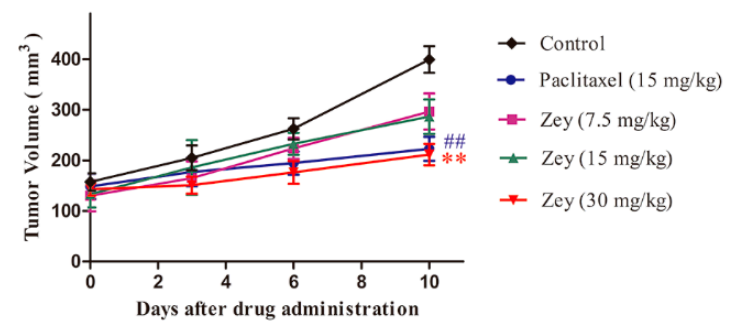

$\mathrm{C}$

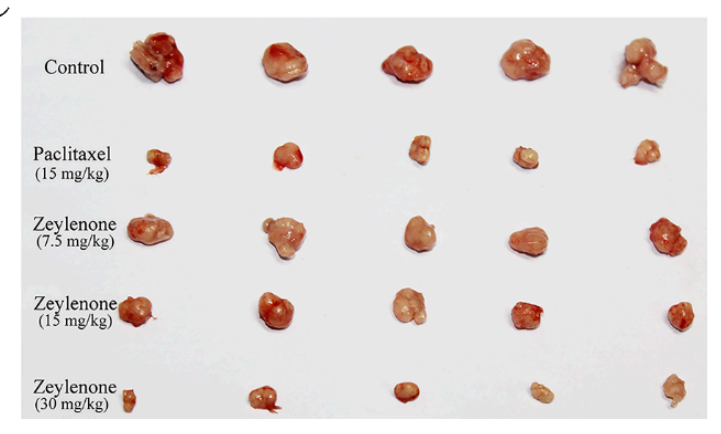

$\mathrm{B}$
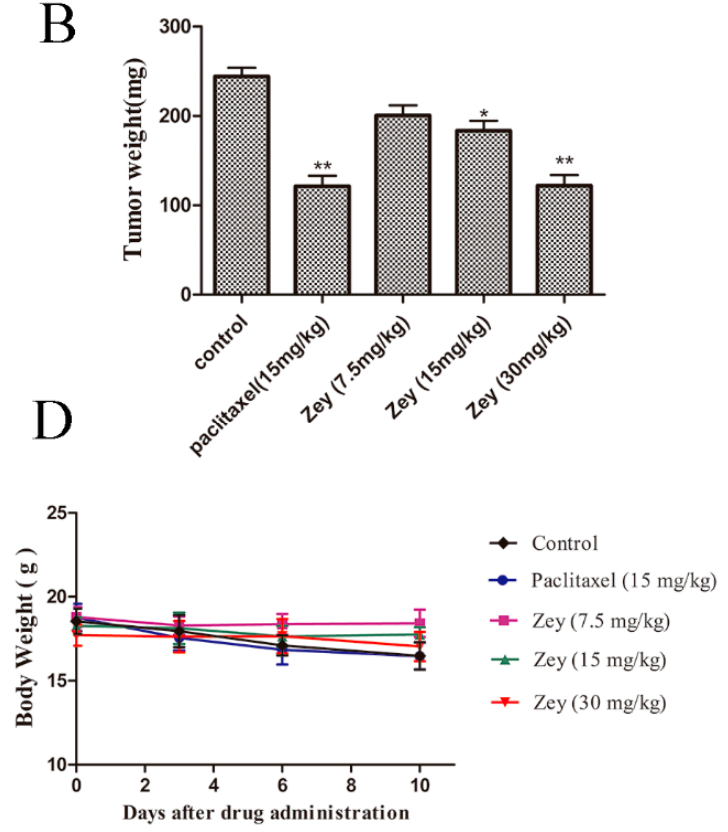

Figure 6. Zey inhibits tumor growth in nude BALB/c mice bearing BGC823 xenografts. BGC823 cells were transplanted subcutaneously to BALB/c nude mice and administered Zey $(7.5,15$, and $30 \mathrm{mg} / \mathrm{kg})$, paclitaxel (15 mg/kg), and saline (as the negative control) for 10 days. (A) Tumor volume was recorded every two days. Mean $\pm \mathrm{SD}(\mathrm{n}=5)$. ${ }^{\# \#} p<0.01$ and ${ }^{* *} p<0.01$ vs. control group. (B) Tumor weight of each group. On day 10 after inoculation, the mice were sacrificed, and the tumor tissues were isolated, weighed, and summarized. Mean $\pm \mathrm{SD}(\mathrm{n}=5) .{ }^{*} p<0.05$ and ${ }^{* *} p<0.01$ vs. control group. (C) Photographs of tumors in each group. (D) Body weight was measured every two days. Mean \pm SD $(n=5)$.

\section{Discussion}

In the present study, we attempted to identify novel functions of Zey and proposed that Zey may be a potent suppressor of gastric cancer cells. On the other hand, the therapeutic efficacy of Zey against gastric cancer and the potential mechanism remained unclear. Therefore, we evaluated the anti-cancer effects of Zey both in vitro and in a mouse xenograft model and further investigated the underlying mechanisms.

Gastric cancer is one of the most common malignant diseases and ranks second in mortality among all cancers worldwide $[19,20]$. Although the detection of early gastric cancer improved, long-term survival remains poor. Firstly, Zey showed strong antitumor activity against SGC7901 and MGC803 cells, and therefore, we performed a further and deeper study of Zey in gastric cancer.

Previous studies showed that apoptosis induction played an important role in the inhibition of cancer cells [21]. Relevant studies confirmed that the imbalance between pro-apoptotic proteins, such as Bax, versus anti-apoptotic factors, such as Bcl-2 and Bcl-xl, can result in decreased mitochondrial membrane integrity, leading to the release of cytochrome $C$ and AIF from mitochondria to the cytoplasm. The released cytochrome $C$ then activates caspase, which finally leads to apoptosis [22]. Consistently, in this study, we found that Zey treatment induced apoptosis by dose-dependently decreasing the levels of anti-apoptotic proteins, including Bcl-2 and Bcl-xl, and increasing the expression of the pro-apoptotic protein Bax. Moreover, Zey led to cell apoptosis with the loss of mitochondrial membrane potential, and apoptotic morphological alterations were also observed in GC cells. Taken together, increased apoptosis might be responsible for cancer growth inhibition by Zey [11]. 
Notably, metastasis, as one of the most important factors of cancer, limits tumor prognosis and increases cancer-related mortality. Therefore, we first found that Zey suppressed both migration and invasion in SGCC7901 and MGC803 cells. To explore the mechanism, we examined the expression of MMPs. Previous studies showed that MMP-2 [23] and MMP-9 [24] were overexpressed in gastric cancer, which accelerated the invasion of tumor cells in vitro and in vivo. In other words, the activation of MMPs led to the spread of tumor cells from their original locations. In our study, we confirmed that Zey treatment markedly reduced MMP-2/9 expression in SGC7901 and MGC803 cells, which implied that Zey, as an inhibitor of MMP expression [25], may be developed into an early treatment to prevent cancer metastasis [26].

In addition, we also focused on the ERK and AKT pathways because they serve critical roles in regulating both the expression of MMPs and cell apoptosis [27]. High expression levels of AKT and phosphorylated (p)-AKT were observed in $74 \%$ and $78 \%$ of gastric tumors, respectively [28]. Additionally, aberrant AKT activation plays a substantial role in invasion and metastasis. Likewise, ERK is an important member of the MAPK family, which plays a central role in regulating the expressions of MMPs [29]. Based on the above results, we tested the related proteins using Western blot assays. As expected, Zey decreased the expressions of AKT, p-AKT, p-mTOR, ERK, and p-ERK, which may partly account for the proliferative inhibition and suppressive migration observed in the GC cells. However, to some extent, a limitation of our study is that we did not identify the inhibitory target of Zey in these pathways. Therefore, further studies are needed.

To determine whether Zey inhibits tumor growth in vivo, a human gastric cancer xenograft mouse model was used. We found that Zey administered at $30 \mathrm{mg} / \mathrm{kg}$ slowed the growth of BGC823 tumors, resulting in a significantly decreased tumor weight on day 10 in the Zey-treated group compared to control mice $(p<0.01)$. Moreover, the treatments of Zey at $30 \mathrm{mg} / \mathrm{kg}$ every two days and paclitaxel at $15 \mathrm{mg} / \mathrm{kg}$ every two days caused similar proliferation inhibition profiles (inhibition rate at $47.95 \%$ and $48.11 \%$, respectively). This was evidence that Zey may be a cytotoxic drug. These findings in vivo were certainly consistent with the observations in vitro and further indicate that Zey may be a potential candidate as an active agent against gastric cancer.

Since Zeylenone was discovered in 1997, we completed pre-clinical studies, including pharmacochemistry [9], structural-activity relationship (SAR) studies [30], drug dosage forms [8], and quantitative analysis of differential protein expression in cervical cancer cells [11]. In the experiments reported here, we mainly discussed the pharmacodynamics and potential mechanism of Zey in gastric cancer. Firstly, we confirmed that Zey inhibited the proliferation of gastric cancer cells in vitro. Then, we went back to the tumor-bearing mice to verify the inhibition of tumor growth in vivo. Finally, we returned to the experiments in vitro again to explore Zey's anti-cancer activity and underlying mechanism. Based on our current preclinical findings, Zey shows promise for development as a novel therapeutic agent in gastric cancer treatment [31]. In the future, when we complete the safety evaluation and pharmacodynamics study, we can go from non-clinical research to clinical research, and we hope that Zey can be used in humans someday.

In summary, our study demonstrated potential effects of Zey on gastric carcinoma using diverse gastric cell lines and a human gastric cancer xenograft mouse model. It may be possible in the future to develop a therapeutic strategy or novel drug for patients with gastric cancer.

\section{Materials and Methods}

\subsection{Materials}

Preparations of Zeylenone (Zey) and mPEG-PLGA-loaded Zeylenone nanomicelles were described previously [8]. Zey used for the in vitro studies was stored as $150 \mathrm{mM}$ solutions in DMSO at $-20^{\circ} \mathrm{C}$ and further diluted to desired working concentrations before use (DMSO concentration $<1 \%$ ). The mPEG-PLGA-loaded Zeylenone nanomicelles used for the in vivo studies were stored in a dry container at room temperature. 
RPMI-1640, DMEM, and fetal bovine serum (FBS) were purchased from Corning Inc. (Corning, NY, USA). MTT, Hoechst 33258, and fluorescent dye JC-1 were purchased from Sigma Aldrich (St. Louis, MO, USA). Antibodies against Bcl-2, Bcl-xl, MMP-9, and MMP-2 were purchased from Santa Cruz Biotechnology (Santa Cruz, CA, USA). Antibodies against Bax, p-AKT, AKT, p-mTOR, pro-caspase3, p-ERK, ERK, and GAPDH, as well as all secondary antibodies, were purchased from Cell Signaling Technology (Danvers, MA, USA). An Annexin V-FITC/PI kit and Matrigel matrix were obtained from BD Biosciences (San Jose, CA, USA).

\subsection{Cell Lines and Cell Culture}

Human gastric carcinoma cell lines, SGC7901, MGC803, and BGC823, and the human normal gastric epithelial cell line, GES-1, were all obtained from the Chinese Academy of Medical Sciences Basic Medicine Cell Center (Beijing, China). SGC7901, MGC803, and BGC823 cells were maintained in RPMI-1640 media containing $10 \%$ FBS and $1 \%$ penicillin/streptomycin in a $37^{\circ} \mathrm{C}$ humidified incubator with $5 \% \mathrm{CO}_{2}$. GES-1 cells were cultured in DMEM media under the same conditions.

\subsection{Ethics Statement and Animals}

All animal experiments and care were performed in accordance with the National Institutes of Health regulations for the care and use of animals in research. All mouse protocols were approved by the Animal Ethics Committee at the Institute of Medicinal Plant Development, Chinese Academy of Medical Sciences (No. SLXD-2017051634) and were in compliance with the Chinese Association for Laboratory Animal Sciences guidelines.

Female BALB/c nude mice (14-16 g) were purchased from SPF Biotechnology Co., Ltd. (Certificate no. SCXK-2016-0002, Beijing, China) and were maintained on a 12-h light/dark cycle with controlled humidity $(50-70 \%)$ and temperature $\left(20-24^{\circ} \mathrm{C}\right)$.

\subsection{Cell Viability Assay by MTT}

Cells cultured in 96-well plates at a density of $5 \times 10^{3}$ cells/well were treated with various concentrations of Zey for $24 \mathrm{~h}$, and cell viability was measured with an MTT assay, as previously described [32].

\subsection{Colony Formation Assay}

Cells (400 cells/well, six-well plates) were treated with Zey $(0,1,2$, or $4 \mu \mathrm{M})$ and were incubated in a $37^{\circ} \mathrm{C}$ humidified atmosphere with $5 \% \mathrm{CO}_{2}$ for 12 days. Cell aggregates containing 50 or more cells were considered colonies. The colonies were fixed with methanol, stained with $0.1 \%$ Coomassie blue, and then counted under a microscope.

\subsection{Hoechst 33258 Staining}

SGC7901 and MGC803 cells were treated with different concentrations of Zey for $24 \mathrm{~h}$. After washing with phosphate-buffered saline (PBS), the cells were stained with Hoechst 33258 $(10 \mu \mathrm{g} / \mathrm{mL})$ for $20 \mathrm{~min}$. Nuclear morphology changes were observed and then captured using a fluorescence microscope (Olympus, Tokyo, Japan).

\subsection{Flow Cytometric Analysis of Apoptosis}

Cells cultured in six-well plates were treated with Zey (SGC7901 and MGC803: 0, 3.3, 6.6, and $13.2 \mu \mathrm{M}$ ) for $12 \mathrm{~h}$ and $24 \mathrm{~h}$, respectively. After harvesting and washing twice with PBS, the cells were stained with annexin-V-FITC and PI according to the manufacturer's directions. The stained cells ( $10^{4}$ cells) were then analyzed immediately using an FACS Calibur flow cytometer (Becton Dickinson, CA, USA), and the results were expressed as a percentage of living (AnnV-, PI-), early apoptotic (AnnV+, PI-), and late apoptotic/dead cells (AnnV+, PI+). Apoptotic rates were 
reported as the percentage of apoptotic cells (including early apoptotic cells and late apoptotic cells) among total cells.

\subsection{JC-1 for Mitochondrial Transmembrane Potential Study}

To investigate whether apoptosis was related to the mitochondrial apoptosis pathway, we measured the change of mitochondrial transmembrane potential using JC-1 [33]. Cells were treated with different concentrations of Zey (SGC7901 and MGC803: 0, 3.3, 6.6, or $13.2 \mu \mathrm{M}$ ) for $24 \mathrm{~h}$. The cells were then collected and stained with $10 \mu \mathrm{g} / \mathrm{mL} \mathrm{JC}-1$ for $30 \mathrm{~min}$ in the dark at $37^{\circ} \mathrm{C}$. After washing twice with PBS, the cells were analyzed by flow cytometry. The highly negative membrane potential in mitochondria produces JC-1 red fluorescence. Loss of mitochondrial transmembrane potential results in green fluorescence and loss of the red fluorescence.

\subsection{Wound-Healing Assays}

Wound-healing assays were performed to investigate migration under Zey treatment. When cell density in 24 -well plates was approximately $90 \%$, a sterile $10-\mu \mathrm{L}$ pipette tip was used to make a linear wound. Cells were washed to remove superfluous floating cells and debris, then co-incubated with different concentrations of Zey $(0,1,2$, or $4 \mu \mathrm{M}$, with a cell viability rate $>93 \%)$ in serum-free RPMI-1640 for an additional $24 \mathrm{~h}$. Wound healing was photographed at 0 and $24 \mathrm{~h}$ using a microscope. The width of the wound was measured by ImageJ software (National Institutes of Health, Bethesda, MD, USA). The wound-healing ratio $(\%)=($ wound area at $0 \mathrm{~h}-$ wound area at $24 \mathrm{~h}) /$ wound area at $0 \mathrm{~h} \times 100 \%$.

\subsection{Invasion and Migration Assay}

For invasion and migration assays, 8.0- $\mu \mathrm{m}$-pore-size transwell chambers (Costar, Corning Inc., Corning, NY, USA) were used [34]. Transwell chambers were coated with Matrigel (dilution 1:5) for the invasion assays. After solidification, the cells $\left(4 \times 10^{4}\right)$ treated with Zey were seeded on the upper transwell chamber insert in 24-well plates and cultured in serum-free RPMI-1640 medium. Meanwhile, $500 \mu \mathrm{L}$ of RPMI-1640 medium containing 10\% FBS was added to the 24-well plates. After $24 \mathrm{~h}$, non-invading cells on the upper surface of the membranes were wiped out by cotton swab and those on the underside were stained with $0.1 \%$ crystal violet and counted under a light microscope with a magnification of $100 \times$. For each replicate, the cells in 10 randomly selected fields were determined, and the counts were averaged. The invasion rate $(\%)=$ the number of migrated cells at 1,2 , or $4 \mu \mathrm{M} /$ the number of migrated cells at $0 \mu \mathrm{M} \times 100 \%$. Similar methods were performed for migration assays, except Matrigel was not used.

\subsection{Western Blot Analyses}

Cells were exposed to Zey (SGC7901 and MGC803: 0, 3.3, 6.6, or $13.2 \mu \mathrm{M}$ ) for $24 \mathrm{~h}$. The detailed steps for electrophoresis, transfer, and immunoblotting were described previously [35]. Antibodies used in this study were mentioned in the Materials and Methods section. All experiments were performed in triplicate, and levels of protein expression were quantified using the Image J software.

\subsection{Tumor Xenograft Study}

A total of $2 \times 10^{7}$ BGC823 human gastric cancer cells were inoculated subcutaneously on the right flanks of mice. The mouse body weight and tumor size were measured every two days. The tumor volume $(\mathrm{V})$ was calculated using the formula $\mathrm{V}=\left(\mathrm{L} \times \mathrm{W}^{2}\right) / 2$, where $\mathrm{L}$ is the largest diameter and $\mathrm{W}$ is the diameter perpendicular to width. When tumors reached $100-150 \mathrm{~mm}^{3}$, the mice were randomized to five groups $(\mathrm{n}=5)$ and treated with vehicle (saline), mPEG-PLGA-loaded Zeylenone micelles (containing Zeylenone 7.5, 15, or $30 \mathrm{mg} / \mathrm{kg}$, once every two days, tail vein injection), and paclitaxel 
( $15 \mathrm{mg} / \mathrm{kg}$, once every two days, tail vein injection) for a total of 10 days. Subsequently, the mice were then euthanized, and the tumors were excised, weighed, fixed, and stored.

\subsection{Statistical Analysis}

All experiments were performed in triplicate, and data were presented as the means \pm SD. The GraphPad Prism 6.0 software (GraphPad Software, La Jolla, CA, USA) was used for statistical analysis. The statistical significance of group differences was analyzed using one-way (ANOVA) and a Tukey's post hoc test ( $t$-test), and $p<0.05$ was considered to be statistically significant.

Author Contributions: S.Y. and L.C. conceived and designed the experiments; S.Y. performed the experiments; L.L., Y.L., and X.X. analyzed the data; S.Y. wrote the manuscript. All authors reviewed the manuscript.

Funding: This work was financially supported by the Fundamental Research Funds for the Central Universities and by the CAMS Innovation Fund for Medical Sciences (CIFMS) (No. 2016-I2M-1-012). This work was also supported by the Key Laboratory of Bioactive Substances and Resources Utilization of Chinese Herbal Medicine, Ministry of Education, and by the Beijing Key Laboratory of Innovative Drug Discovery of Traditional Chinese Medicine (Natural Medicine), and the Translational Medicine, Institute of Medical Plant Development, Peking Union Medical College and Chinese Academy of Medical Sciences.

Conflicts of Interest: The authors declare no conflict of interest.

\section{References}

1. Van Cutsem, E.; Sagaert, X.; Topal, B.; Haustermans, K.; Prenen, H. Gastric Cancer. Lancet 2016, 388, $2654-2664$. [CrossRef]

2. Karimi, P.; Islami, F.; Anandasabapathy, S.; Freedman, N.D.; Kamangar, F. Gastric cancer: Descriptive epidemiology, risk factors, screening, and prevention. Cancer Epidemiol. Biomark. Prev. 2014, 23, 700-713. [CrossRef] [PubMed]

3. Ferlay, J.; Steliarovafoucher, E.; Lortettieulent, J.; Rosso, S.; Coebergh, J.W.; Comber, H.; Forman, D.; Bray, F. Cancer incidence and mortality patterns in europe: Estimates for 40 countries in 2012. Eur. J. Cancer 2013, 49, 1374-1403. [CrossRef] [PubMed]

4. Jemal, A.; Center, M.M.; Desantis, C.; Ward, E.M. Global patterns of cancer incidence and mortality rates and trends. Cancer Epidemiol. Biomark. Prev. 2010, 19, 1893-1907. [CrossRef] [PubMed]

5. Cunningham, S.C.; Kamangar, F.; Kim, M.P.; Hammoud, S.; Haque, R.; Maitra, A.; Montgomery, E.; Heitmiller, R.E.; Choti, M.A.; Lillemoe, K.D. Survival after gastric adenocarcinoma resection: Eighteen-year experience at a single institution. J. Gastrointest. Surg. 2005, 9, 718-725. [CrossRef] [PubMed]

6. Ferro, A.; Peleteiro, B.; Malvezzi, M.; Bosetti, C.; Bertuccio, P.; Levi, F.; Negri, E.; La, V.C.; Lunet, N. Worldwide trends in gastric cancer mortality (1980-2011), with predictions to 2015, and incidence by subtype. Eur. J. Cancer 2014, 50, 1330-1344. [CrossRef] [PubMed]

7. Mehlen, P.; Puisieux, A. Metastasis: A question of life or death. Nat. Rev. Cancer 2006, 6, 449-458. [CrossRef] [PubMed]

8. Hu, X.; Han, R.; Quan, L.H.; Liu, C.Y.; Liao, Y.H. Stabilization and sustained release of zeylenone, a soft cytotoxic drug, within polymeric micelles for local antitumor drug delivery. Int. J. Pharm. 2013, 450, 331-337. [CrossRef] [PubMed]

9. Liao, Y.H.; Xu, L.Z.; Yang, S.L.; Dai, J.; Zhen, Y.S.; Zhu, M.; Sun, N.J. Three cyclohexene oxides from uvaria grandiflora. Phytochemistry 1997, 45, 729-732.

10. Sun, L.H.; Dang, H.X.; Lan-Lan, B.U.; Liao, Y.H.; You-Hua, Y.U.; Liu, X.M. Effects of zeylenone on the proliferation and apoptosis of acute lymphoblastic leukemia cells. J. Tradit. Chin. Med. Univ. Hunan 2012. Available online: http:/ / en.cnki.com.cn/Article_en/CJFDTOTAL-HNZX201209005.htm (accessed on 8 August 2018).

11. Zhang, L.; Jin, J.; Zhang, L.; Hu, R.; Gao, L.; Huo, X.; Liu, D.; Ma, X.; Wang, C.; Han, J. Quantitative analysis of differential protein expression in cervical carcinoma cells after zeylenone treatment by stable isotope labeling with amino acids in cell culture. J. Proteom. 2015, 126, 279-287. [CrossRef] [PubMed]

12. Tsai, J.P.; Lee, C.H.; Ying, T.H.; Lin, C.L.; Lin, C.L.; Hsueh, J.T.; Hsieh, Y.H. Licochalcone a induces autophagy through pi3k/akt/mtor inactivation and autophagy suppression enhances licochalcone a-induced apoptosis of human cervical cancer cells. Oncotarget 2015, 6, 28851-28866. [CrossRef] [PubMed] 
13. Matsuoka, T.; Yashiro, M. The role of pi3k/akt/mtor signaling in gastric carcinoma. Cancers 2014, 6, 1441-1463. [CrossRef] [PubMed]

14. Chen, P.N.; Hsieh, Y.S.; Chiou, H.L.; Chu, S.C. Silibinin inhibits cell invasion through inactivation of both pi3k-akt and mapk signaling pathways. Chem. Biol. Int. 2005, 156, 141-150. [CrossRef] [PubMed]

15. Kilian, M.; Gregor, J.I.; Heukamp, I.; Hanel, M.; Ahlgrimm, M.; Schimke, I.; Kristiansen, G.; Ommer, A.; Walz, M.K.; Jacobi, C.A. Matrix metalloproteinase inhibitor ro 28-2653 decreases liver metastasis by reduction of mmp-2 and mmp-9 concentration in bop-induced ductal pancreatic cancer in syrian hamsters: Inhibition of matrix metalloproteinases in pancreatic cancer. Prostaglandins Leukot. Essent. Fat. Acids 2006, 75, 429-434. [CrossRef] [PubMed]

16. Chen, Z.R.; He, T.F.; Zhao, K.; Xing, C.G. Anti-metastatic activity of fangchinoline in human gastric cancer ags cells. Oncol. Let. 2017, 13, 655-660. [CrossRef] [PubMed]

17. Wan, B.; Zhu, J.; Chang, Q.; Zhou, H.; Shi, Z.; Min, L.; Cai, Y.; Guan, H. Alpha, 2'-dihydroxy-4,4'-dimethoxydihydrochalcone inhibits cell proliferation, invasion, and migration in gastric cancer in part via autophagy. Biomed. Pharmacother. 2018, 98, 709-718. [CrossRef] [PubMed]

18. Gao, J.; Liu, X.; Yang, F.; Liu, T.; Yan, Q.; Yang, X. By inhibiting ras/raf/erk and mmp-9, knockdown of epcam inhibits breast cancer cell growth and metastasis. Oncotarget 2015, 6, 27187-27198. [CrossRef] [PubMed]

19. Piazuelo, M.B.; Correa, P. Gastric cancer: Overview. Colomb. Med. 2013, 44, 192-201. [PubMed]

20. Katona, B.W.; Rustgi, A.K. Gastric cancer genomics: Advances and future directions. Cell. Mol. Gastroenterol. Hepatol. 2017, 3, 211-217. [CrossRef] [PubMed]

21. Giuseppa, P.; Daniela, T.; Claudia, C.; Alessia, G.; Gabriella, D.O. Apoptosis as anticancer mechanism: Function and dysfunction of its modulators and targeted therapeutic strategies. Aging 2016, 8, 603-619.

22. Taylor, R.C.; Cullen, S.P.; Martin, S.J. Apoptosis: Controlled demolition at the cellular level. Nat. Rev. Mol. Cell Biol. 2008, 9, 231-241. [CrossRef] [PubMed]

23. Mönig, S.P.; Baldus, S.E.; Hennecken, J.K.; Spiecker, D.B.; Grass, G.; Schneider, P.M.; Thiele, J.; Dienes, H.P.; Hölscher, A.H. Expression of $\mathrm{mmp}-2$ is associated with progression and lymph node metastasis of gastric carcinoma. Histopathology 2001, 39, 597-602. [CrossRef] [PubMed]

24. Kabashima, A.; Maehara, Y.; Kakeji, Y.; Baba, H.; Koga, T.; Sugimachi, K. Clinicopathological features and overexpression of matrix metalloproteinases in intramucosal gastric carcinoma with lymph node metastasis. Clin. Cancer Res. Off. J. Am. Assoc. Cancer Res. 2000, 6, 3581-3584.

25. Trusolino, L.; Comoglio, P.M. Scatter-factor and semaphorin receptors: Cell signalling for invasive growth. Nat. Rev. Cancer 2002, 2, 289-300. [CrossRef] [PubMed]

26. Murray, G.I.; Duncan, M.E.; Arbuckle, E.; Melvin, W.T.; Fothergill, J.E. Matrix metalloproteinases and their inhibitors in gastric cancer. Gut 1998, 43, 791-797. [CrossRef] [PubMed]

27. Zhu, X.; Jiang, X.; Li, A.; Sun, Y.; Liu, Y.; Sun, X.; Feng, X.; Li, S.; Zhao, Z. S-allylmercaptocysteine suppresses the growth of human gastric cancer xenografts through induction of apoptosis and regulation of mapk and pi3k/akt signaling pathways. Biochem. Biophys. Res. Commun. 2017, 491, 821-826. [CrossRef] [PubMed]

28. Nam, S.Y.; Lee, H.S.; Jung, G.A.; Choi, J.; Cho, S.J.; Min, K.K.; Kim, W.H.; Lee, B.L. Akt/pkb activation in gastric carcinomas correlates with clinicopathologic variables and prognosis. J. Pathol. Microbiol. Immunol. 2003, 111, 1105-1113. [CrossRef]

29. You, J.; Mi, D.; Zhou, X.; Qiao, L.; Zhang, H.; Zhang, X.; Ye, L. A positive feedback between activated extracellularly regulated kinase and cyclooxygenase/lipoxygenase maintains proliferation and migration of breast cancer cells. Endocrinology 2009, 150, 1607-1617. [CrossRef] [PubMed]

30. Liu, A.; Xu, L.; Zou, Z. Studies on chemical constituents of uvaria tonkinensis Var. Subglabra. China J. Chin. Mater. Med. 2009, 34, 567-570.

31. Al-Batran, S.E.; Jager, E.; Scholz, M. Chemotherapy for advanced gastric cancer. J. Clin. Oncol. 2007, 25, 729-730. [CrossRef] [PubMed]

32. Chang, C.T.; Hseu, Y.C.; Thiyagarajan, V.; Lin, K.Y.; Way, T.D.; Korivi, M.; Liao, J.W.; Yang, H.L. Chalcone flavokawain $\mathrm{b}$ induces autophagic-cell death via reactive oxygen species-mediated signaling pathways in human gastric carcinoma and suppresses tumor growth in nude mice. Arch. Toxicol. 2017, 91, 3341-3364. [CrossRef] [PubMed]

33. Chu, J.H.; Zhao, C.R.; Song, Z.Y.; Wang, R.Q.; Qin, Y.Z.; Li, W.B.; Qu, X.J. 1082-39, an analogue of sorafenib, inhibited human cancer cell growth more potently than sorafenib. Biomed. Pharmacother. 2014, 68, 335-341. [CrossRef] [PubMed] 
34. Xu, Y.H.; Li, Z.L.; Qiu, S.F. IFN- $\gamma$ induces gastric cancer cell proliferation and metastasis through upregulation of integrin $\beta 3$-mediated NF-кB signaling. Transl. Oncol. 2018, 11, 182-192. [CrossRef] [PubMed]

35. Zhang, L.; Si, J.; Li, G.; Li, X.; Zhang, L.; Gao, L.; Huo, X.; Liu, D.; Sun, X.; Cao, L. Umbelliprenin and lariciresinol isolated from a long-term-used herb medicine ferula sinkiangensis induce apoptosis and $\mathrm{g} 0 / \mathrm{g} 1$ arresting in gastric cancer cells. R. Soc. Chem. 2015, 5, 91006-91017. [CrossRef]

Sample Availability: Samples of the compound Zeylenone (Zey) are available from the authors.

(C) 2018 by the authors. Licensee MDPI, Basel, Switzerland. This article is an open access article distributed under the terms and conditions of the Creative Commons Attribution (CC BY) license (http://creativecommons.org/licenses/by/4.0/). 